\title{
The Relationship between Living Environment and Oral Function in Elderly Japanese
}

\author{
Naoko Morisaki, Hiroe Uchida, Akiko Miyagawa \\ School of Nursing, Himeji University, Himeji, Japan \\ Email: naoko_morisaki@koutoku.ac.jp
}

How to cite this paper: Morisaki, N. Uchida, H., \& Miyagawa, A. (2019). The Relationship between Living Environment and Oral Function in Elderly Japanese. Advances in Applied Sociology, 9, 71-78. https://doi.org/10.4236/aasoci.2019.92006

Received: December 24, 2018

Accepted: January 30, 2019

Published: February 2, 2019

Copyright (c) 2019 by author(s) and Scientific Research Publishing Inc. This work is licensed under the Creative Commons Attribution International License (CC BY 4.0).

http://creativecommons.org/licenses/by/4.0/

(c) (i) Open Access

\begin{abstract}
This study aims to clarify the current state of oral function among elderly people and to analyze the relation with basic attributes. The subjects of the survey were dependent elderly people receiving nursing care in Japan. We examined the subjects' age, sex, level of care required, living environment (home or facility), and oral functions. Tongue pressure and oral diadochokinesis (OD) were used to evaluate oral function. The relationship between the basic attributes of the elderly subjects and the oral function evaluation value was analyzed by multiple regression analysis. The average value of tongue pressure was $24.70 \pm 10.20 \mathrm{~Pa}$. The average value of OD was $4.7 \pm 1.4 \mathrm{for} / \mathrm{pa} /$, $4.6 \pm 1.3 \mathrm{for} / \mathrm{ta} /$, and $4.3 \pm 1.3 \mathrm{for} / \mathrm{ka} /$. Tongue pressure was found to be significantly related to the degree of care required $(p<0.01)$. The OD recognized syllables of $/ \mathrm{pa} /, / \mathrm{ta} /, / \mathrm{ka} /$ were significantly related to the degree of need for care and living environment $(p<0.05)$. The living environment is thought to affect oral function.
\end{abstract}

\section{Keywords}

Elderly, Oral Function, Living Environment, Relationship

\section{Introduction}

Pneumonia is the third leading cause of death in all ages in Japan, but the number of deaths due to pneumonia especially in elderly people is increasing year by year. 97.3\% of pneumonia deaths in 2016 are elderly people over 65 years old. Many cases of pneumonia in elderly people are said to be aspiration pneumonia caused by aspiration, and in fact, in a national survey by Yamawaki, $80 \%$ of pneumonia that develops in patients aged over 70 years was aspiration pneumonia (Yamawaki, 2009). Aspiration occurs when, owing to a decline in oral function, chewed food does not move smoothly from the pharynx to the stomach. 
From the current research (Kikuchi et al., 1994), it is clear that declining oral function among the elderly is a primary factor leading to severe conditions such as pneumonia, and it is closely related to health prognosis. Furthermore, not only physical concerns but also the relationship between swallowing function and QOL, which is a typical function of oral function, has been clarified (Morisaki, 2017).

For elderly people, oral function is an important factor affecting quality of life, both body (Watanabe et al., 2017; Machida et al., 2017), and mind (Locker et al., 2001; John et al., 2004). However, it is difficult to evaluate the oral function of elderly people, and there are also many unexamined factors. Therefore, this study aims to clarify the current state of oral function among elderly people and to analyze the relation with basic attributes.

\section{Methods}

\subsection{Survey Subjects}

The subjects of the survey were dependent elderly people receiving nursing care in Hyogo Prefecture, Japan, who were able to communicate, and agreed to participate in the research. Hyogo prefecture is located in approximately the center of Japan, facing both the sea and mountains. The percentage of elderly people in Hyogo prefecture in 2018 is $28.3 \%$, close to the average in Japan (27.7\%). For this reason, we consider the subjects of the survey to be a typical representation of elderly people in Japan.

\subsection{Research Methods}

We examined the subjects' basic attributes via a questionnaire and listening comprehension. We interviewed either the subjects themselves, their family members, or facility staff and documented their responses. After conducting the survey, we measured the subjects' oral function in a private room. The measurement of oral function was performed by researchers who are nurses.

\subsection{Survey Items and Evaluation Method}

\section{1) Basic Attributes}

We examined the subject's age, sex, level of care required, and living environment (home or facility). In Japan, the degree of care required is set under the Long Term Care Insurance Law. We evaluate and certify the extent to which elderly people need care and support in daily life by looking at factors such as self-reliance and cognitive function. There are two stages of support required and five stages of need of care for the degree of care required. Level 1 indicates the lightest need for nursing care, and level 5 indicates the most serious need for care.

\section{2) Oral function}

In this study, tongue pressure and oral diadochokinesis (OD) were used to evaluate oral function. 


\section{a) Tongue pressure}

TPM-01, a tongue pressure measuring instrument (manufactured by JMS Co., Ltd., Hiroshima, Japan), was used to measure tongue pressure. This tongue pressure measuring instrument comprises a digital tongue pressure meter, connecting tube, and tongue pressure probe. The balloon section of the tongue pressure probe, which was automatically pressurized as predetermined by the measurement device, was inserted onto the oral part of the tongue while the participant was seated; the participant was instructed to elevate the tip of the tongue to the palate at a maximum force for 5 to 7 seconds, during which the intensity of the force that crushed the balloon was measured. The tongue pressure measurement was performed twice consecutively in accordance with the method described in previous studies (Utanohara et al., 2008), and the mean of the measured values was recorded as the tongue pressure level $(\mathrm{kPa})$. Elderly adults aged 70 years or older are considered to require a tongue pressure level of $20 \mathrm{kPa}$ or greater (Utanohara et al., 2008).

b) $\mathrm{OD}$

OD is regarded by Japan's Preventive Care Project's oral function improvement program as an indicator of articulation function. Subjects are asked to alternately repeat "pa/ta/ka" syllables as quickly as possible, and the frequency of utterances is assessed. For measurement, an automatically counting OD-measuring instrument called Kenkou-kun (manufactured by Takei Scientific Instruments) was used (Ito et al., 2009). Five second intervals of vocalization were performed in a quiet room, and from that five second interval a one-second average utterance rate was calculated. Furthermore, in a survey of elderly residents over 75 living in the region, the lower limit reference value for OD was established as /pa/ 3.8, /ta/ 3.3, / ka/ 2.6 (Hara et al., 2013).

\subsection{Analysis Methods}

The relationship between the basic attributes of the elderly subjects and the oral function evaluation value (tongue pressure/OD) was analyzed by multiple regression analysis. The significance level in analysis was set to less than 0.05 . For the series of analyses, statistical software IBM SPSS Ver. 25.0 was used.

\subsection{Ethical Considerations}

For this research, we received consent from the target persons and the persons concerned with the elderly home by orally describing the objectives, procedures, the optional nature of participation in research, protection of personal information, publication of results, etc., using a document. At the same time, through similar facilities, we obtained similar consent from family members of the target group.

This research has been approved by the Himeji University Nursing College Research Ethics Review Committee (approval number: 2016-N005). 


\section{Results}

\subsection{Basic Attributes}

The number of subjects was 282, with an average age of $81.6 \pm 7.2$ years old, 104 men $(36.9 \%)$, and 178 females (63.1\%). As for nursing care requirements, eleven people $(3.9 \%)$ did not require care, 46 people (16.3\%) required support level 1 , 49 people (17.4\% required care level 2, 39 people $(13.8 \%)$ required care level 3, 17 people $(6.0 \%)$ required care level 4 , and 13 people $(4.6 \%)$ required care level 5. Regarding their living environments, 182 participants (64.5\%) were living at home, and $100(35.5 \%)$ were living at a facility.

\subsection{Oral Function}

Tongue pressure value and OD value are shown.

\section{1) Tongue pressure}

The average value of tongue pressure was $24.70 \pm 10.20 \mathrm{~Pa}$. The distribution of tongue pressure values is shown in Figure 1. There were $82(29.1 \%)$ participants with less than $20 \mathrm{kPa}$.

\section{2) $\mathrm{OD}$}

The average value of $\mathrm{OD}$ was $4.7 \pm 1.4 \mathrm{for} / \mathrm{pa} /, 4.6 \pm 1.3 \mathrm{for} / \mathrm{ta} /$, and $4.3 \pm 1.3$ for $/ \mathrm{ka} /$. Figures 2-4 show the distribution of each value. Participants who were below the lower limit standard for people over 75 for /pa/ (3.8) numbered 69 (24.5\%), those below the limit for /ta/ (3.3) numbered 51 (18.1\%), and those below the limit for $/ \mathrm{ka} /(2.6)$ numbered 31 (11.0\%).

\subsection{Association Analysis of Basic Attributes and Oral Function}

Stepwise multiple regression analysis was performed with the oral function evaluation value as a dependent variable. The analysis results are shown in Table 1 and Table 2. The dependent variables were the values of tongue pressure and $\mathrm{OD}$, which are oral function evaluation values; input variables were age, gender,

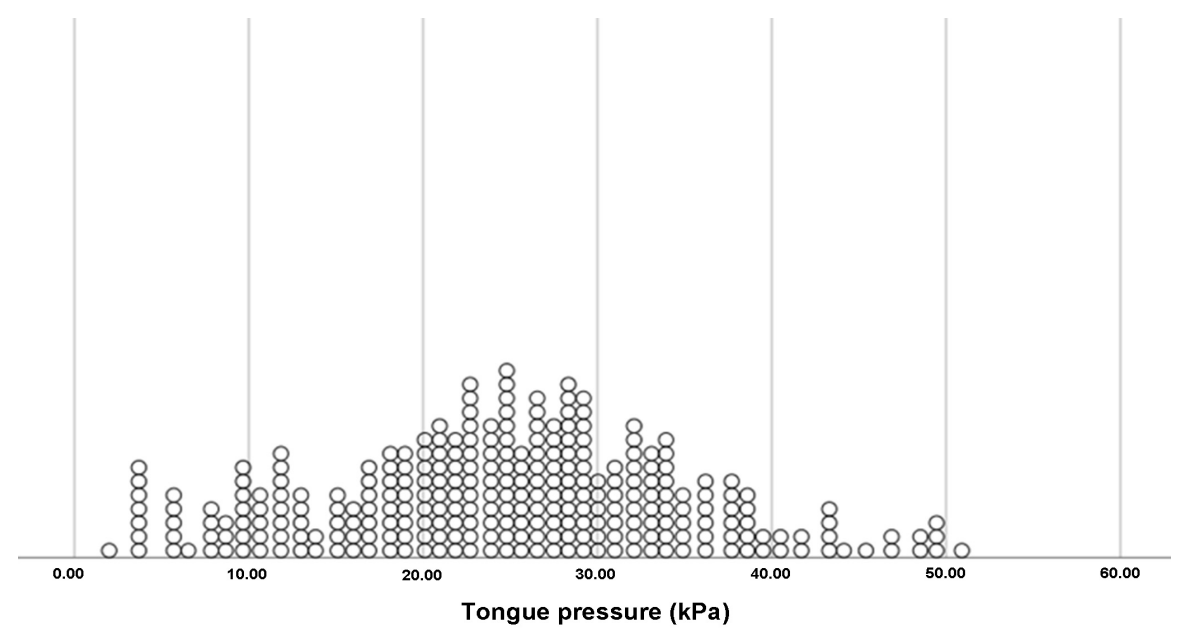

Figure 1. Tongue pressure $(\mathrm{N}=282)$. 


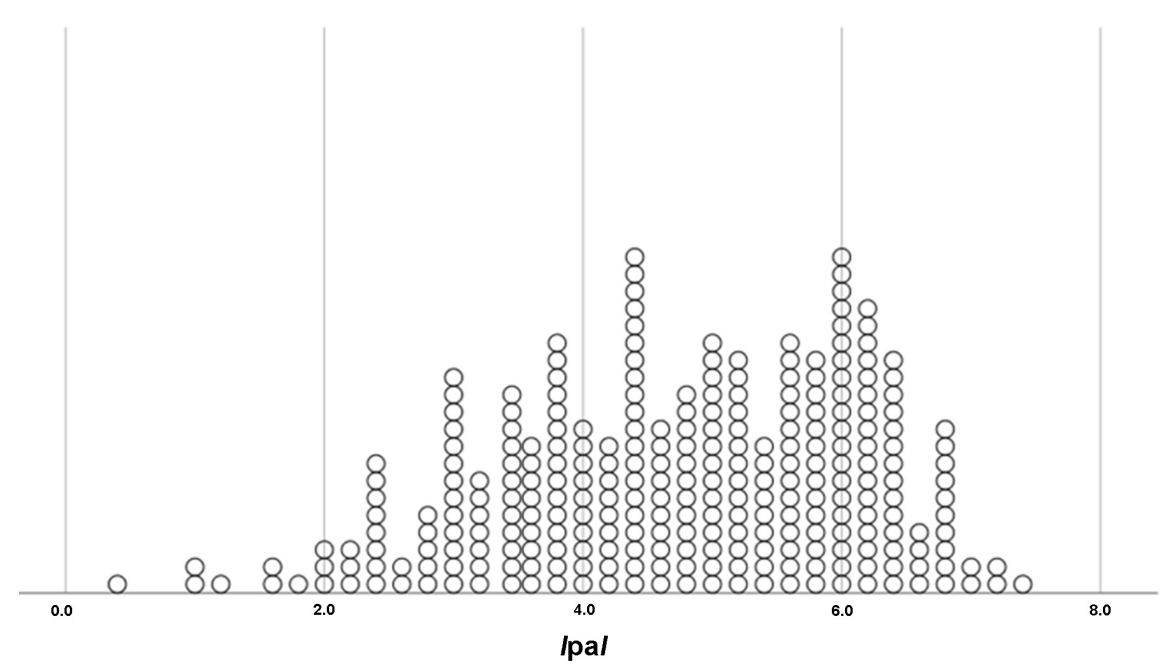

Figure 2. /pa/ of OD $(\mathrm{N}=282)$.

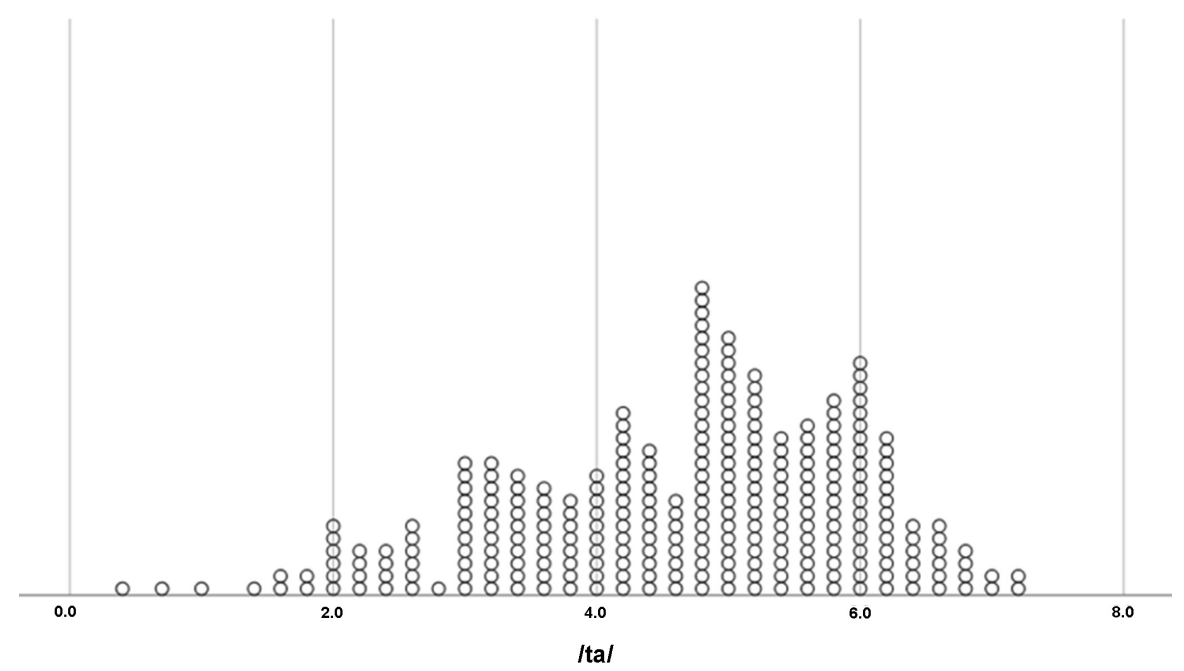

Figure 3. /ta/ of OD $(\mathrm{N}=282)$.

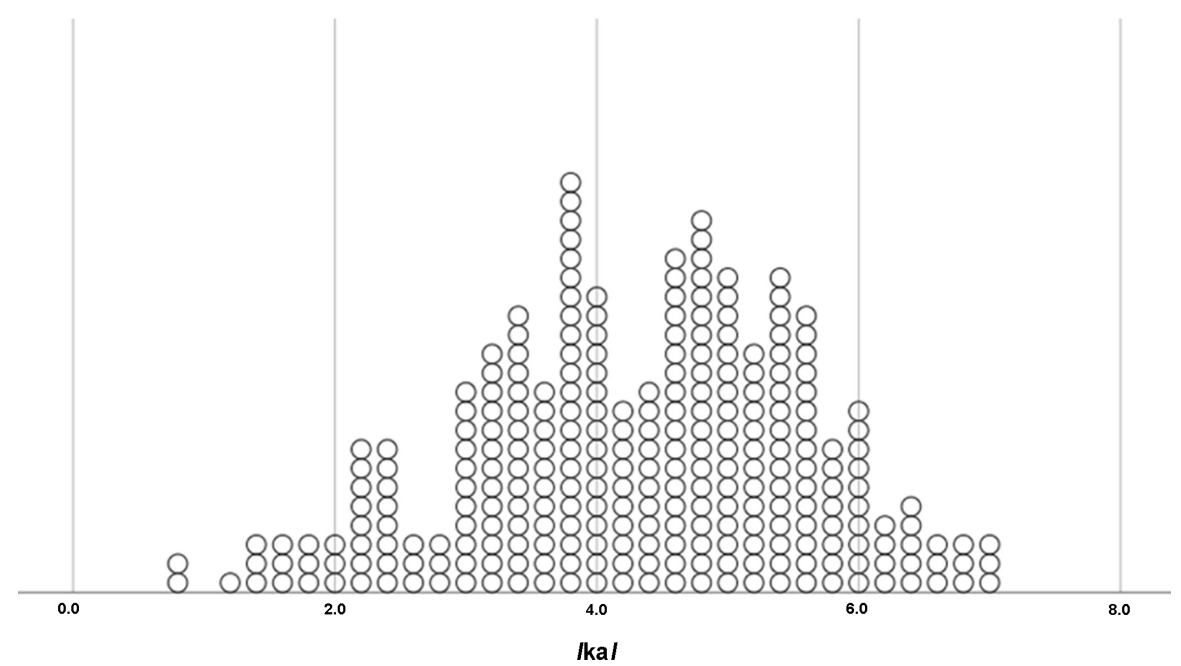

Figure 4. /ka/of OD $(\mathrm{N}=282)$. 
Table 1. Analysis of tongue pressure $(\mathrm{N}=282)$.

\begin{tabular}{lcccc}
\hline Dependent variables & Input variables & $\beta$ & $\mathrm{t}$ & $p$ \\
\hline Tongue pressure & Degree of care required & -0.28 & -4.87 & $<0.01^{* *}$ \\
\hline $\begin{array}{l}\text { Stepwise multiple regression analysis; } / \mathrm{pa} /: \mathrm{R}=0.41, \mathrm{R}^{2}=0.17, / \mathrm{ta} /: \mathrm{R} \\
\text { 0.01. }\end{array}$ & & &
\end{tabular}

Table 2. Analysis of OD $(\mathrm{N}=282)$.

\begin{tabular}{ccccc}
\hline Dependent variables & Input variables & $\beta$ & $\mathrm{t}$ & $p$ \\
\hline \multirow{2}{*}{$/ \mathrm{pa} /$} & Degree of care required & -0.32 & -5.60 & $<0.01^{\star *}$ \\
& Living environment & -0.18 & -3.11 & $<0.01^{\star *}$ \\
& Degree of care required & -0.36 & -6.28 & $<0.01^{\star *}$ \\
& Living environment & -0.12 & -2.14 & 0.03 \\
& Degree of care required & -0.36 & -6.28 & $<0.01^{\star *}$ \\
& Living environment & -0.16 & -2.77 & $<0.01^{\star *}$ \\
\hline
\end{tabular}

Stepwise multiple regression analysis; $\mathrm{R}=0.28, \mathrm{R}^{2}=0.08 ;{ }^{\star} p<0.05,{ }^{\star *} p<0.01$.

degree of care required, and living environment. As for the living environment, I analyzed it as 1 for home and 0 for facility.

Tongue pressure was found to be significantly related to the degree of care required $(p<0.01)$. The lower the degree of care required, the higher the tongue pressure. The OD recognized syllables of $/ \mathrm{pa} /, / \mathrm{ta} /, / \mathrm{ka} /$ were significantly related to the degree of need for care and living environment $(p<0.05)$. Those with lower degrees of care required and those living at home had high OD values.

\section{Discussion}

In this survey, we clarified the current state of oral function of elderly people. Although tongue pressure is the force required to feed the bolus to the pharynx at the time of swallowing, it is found that reduction in tongue pressure among the elderly also affects chewing function (Kikutani et al., 2009) and meal form (Tsuga et al., 2004). Among these subjects, about 30\% have not reached $20 \mathrm{kPa}$ (Tsuga et al., 2004), which is a standard measure of tongue pressure among those over 70, and there is concern about potential adverse effects on meal intake.

Regarding OD, although there are differences depending on the syllables of $/ \mathrm{pa} /, / \mathrm{ta} /, / \mathrm{ka} /$, there were $10 \%$ to $20 \%$ of those who were below the lower limit reference value for those aged 75 or over. /pa/ is the function of the lip, /ta/ is the function of the front of the tongue, and $/ \mathrm{ka} /$ is to evaluate the function behind the tongue (Hartelius \& Lillvik, 2003), so it seems these results are due to the deterioration of the function of the lip and tongue.

Although there are some differences depending on the evaluation index, it is thought that there are a considerable number of elderly people who have experienced some deterioration of oral function. Therefore, we need to further strengthen efforts to maintain or improve the oral function of elderly people. Oral exercises are effective for improving the oral function of elderly people (Morisaki, 2018). Therefore, we believe it is necessary to implement oral cavity 
exercises as part of daily exercise routines.

In the results of this analysis, the oral function of the elderly was related to the degree of care required. It has been said that the oral function of elderly people is related to the function of life (Kikutani, 2017), and this result supports that view. Moreover, based on the results of OD analysis, elderly people who live at home are in better oral condition in terms of articulation function than those who live in a facility. Therefore, the living environment is thought to affect oral function. I would like to clarify in future studies what factors of living at home affect oral function.

\section{Conclusion}

From the results of this survey, the following was found.

1) There are quite a few elderly people whose oral function has declined.

2) Tongue pressure is related to degree of care required, and OD is related to both degree of care required and living environment.

\section{Acknowledgements}

I would like to thank the elderly subjects who participated and all persons affiliated with elderly nursing home health facilities who cooperated in this research. This research was carried out under the auspices of the Japan Society for the Promotion of Science Grant-in-Aid for Scientific Research/funded research (C) (issue number: 16K12228). There is no COI status to declare.

\section{Conflicts of Interest}

The authors declare that they have no competing interests.

\section{References}

Hara, S., Miura, H., \& Yamasaki, K. (2013). Oral Diadochokinesis among Japanese Aged over 55 Years: Analysis of Standard Values. Japan Journal of Gerodontology, 50, 258-263.

Hartelius, L., \& Lillvik, M. (2003). Lip and Tongue Function Differently Affected in Individuals with Multiple Sclerosis. Folia Phoniatrica et Logopaedica, 55, 1-9. https://doi.org/10.1159/000068057

Ito, K., Yoshihara, A., Takano, N., Ishigami, K., Seida, Y., Inoue, M., Kitahara, M., \& Miyazaki, H. (2009). A Comparison of Methods for the Measurement of Oral Diadochokinesis. Journal of Gerodontology, 24, 48-54.

John, M. T., Koepsell, T. D., Hujoel, P., Miglioretti, D. L., LeResche, L., \& Micheelis, W. (2004). Demographic Factors, Denture Status and Oral Health-Related Quality of Life. Community Dentistry and Oral Epidemiology, 32, 125-132. https://doi.org/10.1111/j.0301-5661.2004.00144.x

Kikuchi, R., Watabe, N., Konno, T., Mishina, N., Sekizawa, K., \& Sasaki, H. (1994). High Incidence of Silent Dysphagia in Elderly Patients with Community-Acquired Pneumonia. American Journal of Respiratory and Critical Care Medicine, 150, 251-253. https://doi.org/10.1164/ajrccm.150.1.8025758

Kikutani, T. (2017). Response to Oral Frail in Dental Clinic. Japan Journal of Gerodontology, 31, 412-416. 
Kikutani, T., Tamura, F., Nishiwaki, K., Kodama, M., Suda, M., Fukui, T., et al. (2009). Oral Motor Function and Masticatory Performance in the Community-Dwelling Elderly. Odontology, 97, 38-42. https://doi.org/10.1007/s10266-008-0094-z

Locker, D., Matear, D., Stephens, M., Lawrence, H., \& Payne, B. (2001). Comparison of the GOHAI and OHIP-14 as Measures of the Oral Health-Related Quality of Life of Elderly. Community Dentistry and Oral Epidemiology, 29, 373-381. https://doi.org/10.1034/j.1600-0528.2001.290507.x

Machida, N., Tohara, H., Hara, K., Kumakura, A., Wakasugi, Y., Nakane, A., \& Monakuchi, S. (2017). Effects of Aging and Sarcopenia on Tongue Pressure and Jaw-Opening Force. Geriatrics \& Gerontology International, 17, 295-301. https://doi.org/10.1111/ggi.12715

Morisaki, N. (2017). Relationship between Swallowing Functions and Health-Related Quality of Life among Community-Dwelling Dependent Older Individuals. Japan Journal of Nursing Science, 14, 353-363. https://doi.org/10.1111/jins.12168

Morisaki, N. (2018). Effects of Oral Exercise on Oral Function among Japanese Dependent Elderly Individuals Living in Nursing Facilities. International Journal of Nursing and Clinical Practices, 5.

Tsuga, K., Yoshida, M., Urabe, H., Hayashi, R., Yoshikawa, M., Utanohara, Y., et al. (2004). Effect of General Condition and Tongue Pressure on Meal Form Selection for Elderly Care Recipient. Journal of Japanese Society for Masticatory Science and Health Promotion, 14, 62-67.

Utanohara, Y., Hayashi, R., Yoshikawa, M., Yoshida, M., Tsuga, K., \& Akagawa, Y. (2008). Standard Values of Maximum Tongue Pressure Taken Using Newly Developed Disposable Tongue Pressure Measurement Device. Dysphagia, 23, 286-290. https://doi.org/10.1007/s00455-007-9142-z

Watanabe, Y., Hirano, H., Arai, H., Morishita, S., Ohara, Y., Edahiro, A., Murakami, M., Shimada, H., Kikitani, T., \& Suzuki, T. (2017). Relationship between Frailty and Oral Function in Community-Dwelling Elderly Adults. Journal of the American Geriatrics Society, 65, 66-76. https://doi.org/10.1111/jgs.14355

Yamawaki, M. (2009). Epidemiology of Dysphagia Pneumonia. Sogo Rihabiriteshon, 37, 105-109. 